\title{
Maternal mental health and social support: effect on childhood atopic and non-atopic asthma symptoms
}

\author{
Letícia Marques dos Santos, ${ }^{1}$ Darci Neves dos Santos, ${ }^{1}$ Laura Cunha Rodrigues, ${ }^{2}$ \\ Maurício Lima Barreto ${ }^{1}$
}

1 Department of Collective Health, Institute of Collective Health, Federal University of Bahia, Salvador, Brazil ${ }^{2}$ London School of Hygiene and Tropical Medicine, London, UK

\section{Correspondence to} Dr Letícia Marques dos Santos, Instituto de Saúde Coletiva, Universidade Federal da Bahia, Rua Basílio da Gama, s/n Campus Universitário Canela, Salvador, Bahia 40110040 Brazil. marquesleticia@hotmail.com

Accepted 8 February 2012

Published Online First 4 November 2012

\section{ABSTRACT}

Background Atopic and non-atopic asthma have distinct risk factors and immunological mechanisms, and few studies differentiate between the impacts of psychosocial factors on the prevalence of these disease phenotypes. The authors aimed to identify whether the effect of maternal mental health on prevalence of asthma symptoms differs between atopic and non-atopic children, taking into account family social support.

Methods This is a cross-sectional study of 1013 children participating in the Social Change Allergy and Asthma in Latin America project. Psychosocial data were collected through a household survey utilising Self-Reporting Questionnaire and Medical Outcome Study Social Support Scale. Socioeconomic and wheezing information was obtained through the questionnaire of the International Study of Allergy and Asthma in Childhood, and level of allergen-specific IgE was measured to identify atopy. Polytomous logistic regression was used to estimate the association between maternal mental health, social support and atopic and non-atopic wheezing. Effect modification was evaluated through stratified polytomous regression according to social support level.

Results Maternal mental disorder had the same impact on atopic and non-atopic wheezing, even after adjusting for confounding variables. Affective, material and informational supports had protective effects on nonatopic asthma, and there is some evidence that social supports may act as a buffer for the impact of maternal mental disorder on non-atopic wheezing.

Conclusion Poor maternal mental health is positively associated with wheezing, independent of whether asthma is atopic or non-atopic, but perception of high levels of social support appears to buffer this relationship in non-atopic wheezers only.

\section{INTRODUCTION}

Although atopic and non-atopic asthma manifest distinct risk factors and immunological mechanisms, ${ }^{1-8}$ few studies examine the impact of psychosocial factors on each of these disease phenotypes. Furthermore, the majority of studies do not address the possible interaction between a number of psychosocial factors shared by both the mother and the asthmatic child within the family environment; this impedes a more robust understanding of the dynamics of the disease.

Living with care givers who have common mental disorders (CMD) is an important determinant of childhood asthma. Symptoms of anxiety, depression and maternal stress are associated with prevalence and severity of both asthma phenotypes and can alter the child's immunological profile. ${ }^{9-18}$
Both asthma prevalence and maternal CMD are associated with the existence of family social support. It is assumed that social support increases the sense of parental self-efficacy and self-esteem, facilitates access to healthcare and increases instrumental and informational support, thereby enabling adequate management of the disease and preventing both the severity and the exacerbation of childhood asthma. ${ }^{11} 19-21$ Family social support seems therefore to be an important potential moderator of the impact of maternal CMD on childhood asthma prevalence and morbidity.

We identified a gap in joint analysis of both the impact of maternal CMD and family social support on prevalence of childhood asthma, specifically of studies that examine the underlying mechanisms for the expression of these distinct disease profiles. The present study addresses this gap by investigating whether the effect of maternal $\mathrm{CMD}$ on prevalence of childhood asthma symptoms differs between atopic and non-atopic children in the presence of maternal social support.

\section{METHODS}

\section{Study design}

This is a cross-sectional analysis of a population cohort of children aged between 4 and 12 years old in the city of Salvador, Brazil, part of the Social Change Allergy and Asthma in Latin America (SCAALA) programme. Details of the study design and methods are presented elsewhere. ${ }^{122}$

\section{Study population and sample}

The SCAALA-Salvador project had 1445 children who were participants in a previous cohort study and had completed all follow-up data. These children were randomly selected from 20000 residents of varying economic levels and environmental conditions. $^{22}$ The sample for this study comprised 1096 children whose questionnaires about mental health were answered by the child's biological mother. From this sample, 1013 had complete data for all the covariates studied. Fifty-five questionnaires presented with missing data regarding social support, 24 regarding history of pneumonia and four regarding maternal level of education. In comparing the 83 subjects with missing data with the total sample, we noted that the prevalence of asthma symptoms was very similar (data not shown).

\section{Instruments}

An adapted questionnaire from the International Study of Allergy and Asthma in Childhood 
(ISAAC) - Phase II ${ }^{22} 23$ was utilised to evaluate the prevalence of childhood asthma symptoms and to collect information about exposure factors. It is a standardised pre-coded and validated questionnaire, completed according to care giver reports about asthma and allergy symptoms, child's health history and family socioeconomic level.

Blood samples were collected to assess allergen-specific IgE serum levels and were performed through radioimmunoassay (RAST) utilising commercial kits and the ELISA test, standardised in the group laboratory. Additional details have been published by Barreto et al. ${ }^{22}$

We used the Self Reporting Questionnaire (SRQ-20) to measure maternal mental health. This questionnaire was developed by WHO and has been validated for the Brazilian population. ${ }^{24}$ It is composed of 20 questions about the presence of depressive symptoms, dysthymia, phobia/anxiety, somatization and neurasthenia. Brazilian studies indicate high sensitivity $(85 \%)$ and specificity (80\%) for this instrument when compared with psychiatric diagnostic interview.

A Social Support Scale was applied to the mothers; this had originally been developed for the Medical Outcomes Study (MOS). It is composed of 19 items with responses on a Likert scale that identify the frequency with which social support is perceived. The items were organised to cover five dimensions of social support: material, affective, positive social interaction, emotional and informational. The raw score was calculated for each dimension through the sum of points attributed to the items; the higher the score, the greater the perception of social support. For the purposes of analysis, the scores were dichotomised, using the first distribution quartile as a cut-off point. The scale has been adapted and validated in Brazil and presents high internal consistency levels and moderate item-scale correlation, enabling it to be used as a measure of perceived social support. $^{25}$

\section{Outcome measures}

Asthma symptoms were defined as the presence of wheezing in the last 12 months in association with at least one of the following conditions: having a medical diagnosis of asthma, difficulty talking due to wheezing, waking in the night at least once a week and wheezing after physical exercise.

Atopy was defined as the presence of a specific IgE for at least one of the most important aeroallergens (Dermatophagoides pteronyssinus, Blomia tropicalis, Blatella germanica, cat and dog). The cut-off point was $0.70 \mathrm{kU} / \mathrm{l}$; a reliable value for detecting specific IgE through the RAST technique.

Individuals who presented with asthma symptoms in association with an IgE above $0.70 \mathrm{kU} / \mathrm{l}$ were classified as atopic wheezing (code 1). Those who presented with asthma symptoms but did not have a detectable IgE were classified as non-atopic wheezing (code 2).

Reference groups were coded as zero and chosen according to studied outcome. The comparison group for non-atopic wheezing was composed of children who did not present either asthma symptoms or detectable IgE. For atopic wheezing, our reference group was the atopic non-asthmatic children, in order to avoid the potential bias of risk factors independently associated with atopy. $^{1}$

\section{Main exposure measures}

Suspected maternal CMD was defined by eight or more positive responses to the SRQ-20, in line with previous studies involving Brazilian population. ${ }^{26}$ The variable was coded 0 : not suspected and 1: suspected.

\section{Covariates}

Covariates were organised according to the impact on the outcome studied. We took individual characteristics as child's sex, age and history of pneumonia. Maternal characteristics

Table 1 Individual and family environment characteristics by suspected maternal CMD ( $\mathrm{N}=1013)$

\begin{tabular}{|c|c|c|}
\hline & $\begin{array}{l}\text { Suspected CMD } \\
(\mathrm{N}=382)\end{array}$ & $\begin{array}{l}\text { No suspected CMD } \\
(\mathrm{N}=631)\end{array}$ \\
\hline \multicolumn{3}{|l|}{ Individual characteristics } \\
\hline Sex & $\mathrm{n}(\%)$ & $\mathrm{n}(\%)$ \\
\hline Male & $200(52.4)$ & $341(54.0)$ \\
\hline Female & $182(47.6)$ & $290(46.0)$ \\
\hline \multicolumn{3}{|l|}{ Age (years) } \\
\hline$\leq 7$ & $244(63.9)$ & $353(55.9)$ \\
\hline$\geq 8$ & $138(36.1)$ & $278(44.1)$ \\
\hline \multicolumn{3}{|l|}{ Atopic asthma symptoms } \\
\hline Yes & $62(16.2)$ & 69 (10.9) \\
\hline No & $249(65.2)$ & $495(78.4)$ \\
\hline \multicolumn{3}{|c|}{ Non-atopic asthma symptoms } \\
\hline Yes & $71(18.6)$ & $67(10.6)$ \\
\hline No & $249(65.2)$ & $495(78.4)$ \\
\hline \multicolumn{3}{|l|}{ History of pneumonia } \\
\hline Yes & $85(22.3)$ & $97(15.4)$ \\
\hline No & $297(77.8)$ & $534(84.6)$ \\
\hline Maternal characteristics & $\mathrm{n}(\%)$ & $\mathrm{n}(\%)$ \\
\hline \multicolumn{3}{|l|}{ History of asthma } \\
\hline Yes & $67(17.6)$ & $67(10.6)$ \\
\hline No & $315(82.5)$ & $564(89.4)$ \\
\hline \multicolumn{3}{|l|}{ Educational level } \\
\hline Primary & $95(24.9)$ & $129(20.4)$ \\
\hline More than primary & $180(47.1)$ & $304(48.2)$ \\
\hline More than secondary & $107(28.0)$ & $198(31.4)$ \\
\hline \multicolumn{3}{|l|}{ Affective support } \\
\hline High & $233(61.0)$ & $493(78.1)$ \\
\hline Low & $149(39.0)$ & $138(21.9)$ \\
\hline \multicolumn{3}{|l|}{ Material support } \\
\hline High & $242(63.4)$ & $468(74.2)$ \\
\hline Low & $140(36.6)$ & $163(25.8)$ \\
\hline \multicolumn{3}{|l|}{ Positive social interaction } \\
\hline High & $225(58.9)$ & $483(76.5)$ \\
\hline Low & $147(41.1)$ & $148(23.5)$ \\
\hline \multicolumn{3}{|l|}{ Emotional support } \\
\hline High & $248(64.9)$ & $503(79.7)$ \\
\hline Low & $134(35.1)$ & $128(20.3)$ \\
\hline \multicolumn{3}{|l|}{ Informational support } \\
\hline High & $240(62.8)$ & $469(74.3)$ \\
\hline Low & $142(37.2)$ & $162(25.7)$ \\
\hline \multicolumn{3}{|l|}{ Family income } \\
\hline$<1 \mathrm{MW}$ & $225(58.9)$ & $325(51.5)$ \\
\hline$\geq 1<2 \mathrm{MW}$ & $108(28.3)$ & $200(31.7)$ \\
\hline$\geq 2 \mathrm{MW}$ & $49(12.8)$ & $106(16.8)$ \\
\hline Family environment & $\mathrm{n}(\%)$ & $\mathrm{n}(\%)$ \\
\hline \multicolumn{3}{|l|}{ Exposure to tobacco } \\
\hline Yes & $119(31.2)$ & $144(22.8)$ \\
\hline No & $263(68.8)$ & 487 (77.2) \\
\hline \multicolumn{3}{|l|}{ Exposure to mould } \\
\hline Yes & $257(67.3)$ & $395(62.6)$ \\
\hline No & $125(32.7)$ & $236(37.4)$ \\
\hline \multicolumn{3}{|l|}{ Number of children } \\
\hline$<2$ & $234(61.4)$ & $354(56.2)$ \\
\hline$\geq 2$ & $147(38.6)$ & $276(43.8)$ \\
\hline
\end{tabular}

$\mathrm{CMD}$, common mental disorder. 
included history of asthma, educational level, family income and affective, material, positive social interaction, emotional and informational social supports. We took family environmental characteristics as exposure to mould, exposure to tobacco and number of children.

\section{Data analysis}

Psychosocial questionnaires were administered at home by a team of one psychology co-ordinator and four supervised psychology students. This team was trained by a qualified professional and the students were constantly and directly supervised by a specialist. After coding, data were entered into the EPI INFO V.6 by two different individuals, in order to reduce consistency errors. Then, the database was converted into STATA software program V.10.0, cleaned up and corrected for analysis.

Descriptive analysis was carried out to identify the prevalence of atopic and non-atopic asthma symptoms and to describe all the co-variables studied, according to suspected maternal CMD. We then estimated the non-adjusted $\mathrm{OR}$ through simple logistic polytomous regression, in order to identify associations between the covariates and atopic and non-atopic asthma symptoms. Those which demonstrated an association with at least one asthma outcome were inserted into a multiple logistic polytomous regression model to estimate the adjusted OR of association between maternal $\mathrm{CMD}$, social support and child atopic and non-atopic asthma symptoms. ${ }^{1} 27$

We selected potentially confounding variables that were associated with exposure among those without the disease and, simultaneously, with the outcome among the non-exposed. After this, we utilised backwards multivariate logistic polytomous regression and considered presence of confounders when the measurement of association of the complete model and that of the reduced model differed by $10 \%$ or more. We also conducted the maximum likelihood test using the parameter $\chi^{2}$ with a $p$ value $\leq 0.05$ to identify the best model. Some variables which were not confounder for the association between asthma symptoms and maternal CMD were kept in the model because they are usually referred to in the asthma literature.

To identify effect modification, we stratified the study population according to the variables of affective, material and informational social support and then conducted a multiple logistic polytomous regression to estimate the adjusted $O R$ of association between maternal CMD and atopic and non-atopic wheezing. Effect modification was identified by the lack of overlap of ORs with strata-specific CIs.

The model's goodness of fit was verified by deviance $\chi^{2}$ (256.17; $p$ value $=0.269$ ), confirming that the model fitted well with the observed data. All the analyses were conducted using the STATA V.10 programme, except for the deviance calculation, for which we used the SPSS V.11.0 programme.

\section{Ethical considerations}

The study was approved by the National Ethics Committee in 2005, registration number 047-05/CEP-ISC FR-78168. Parents or guardians signed the Free and Informed Consent Form that contained detailed information about the research's data collection procedures. Guardians were informed of results that suggested a need for medical/psychological care and were provided with relevant health service information.

\section{RESULTS}

Distribution of child sex was similar among mothers both with and without CMD symptoms. On the other hand, mothers with CMD symptoms had children who were mostly under 7 years old (63.9\%) and the greatest prevalence of atopic (16.2\%) and non-atopic (18.6\%) asthma symptoms and a higher frequency of history of pneumonia (22.3\%). Furthermore, they also presented a higher frequency of asthma history $(17.6 \%)$ and less affective (61\%) and material (63.4\%) social supports, less positive social interaction (58.9\%), emotional (64.9\%) and

Table 2 Non-adjusted and adjusted OR for atopic and non-atopic asthma symptoms, according to individual, maternal and family environment characteristics $(\mathrm{N}=1013)$

\begin{tabular}{|c|c|c|c|c|}
\hline \multirow{2}{*}{$\begin{array}{l}\text { Variables } \\
\text { Co-variates }\end{array}$} & \multicolumn{2}{|c|}{ Atopic asthma symptoms $(\mathrm{N}=131)$} & \multicolumn{2}{|c|}{ Non-atopic asthma symptoms $(\mathrm{N}=138)$} \\
\hline & Crude OR (95\% CI) & Adjusted OR* $(95 \% \mathrm{CI})$ & Crude OR (95\% CI) & Adjusted $0 R^{*}(95 \% \mathrm{Cl})$ \\
\hline \multicolumn{5}{|l|}{ Individual characteristics } \\
\hline Male sex & $0.80(0.52$ to 1.24$)$ & - & $1.18(0.81$ to 1.72$)$ & - \\
\hline Age $\leq 7$ years & $1.72(1.11$ to 2.66$)$ & - & $2.13(1.41$ to 3.22$)$ & - \\
\hline History of pneumonia & $2.28(1.38$ to 3.78$)$ & - & 2.14 (1.36 to 3.39$)$ & - \\
\hline \multicolumn{5}{|l|}{ Maternal characteristics } \\
\hline History of asthma & $3.70(1.96$ to 6.98$)$ & - & 1.67 (1.02 to 2.76$)$ & - \\
\hline Primary level of education & $1.22(0.69$ to 2.18$)$ & - & 2.02 (1.18 to 3.45$)$ & - \\
\hline More than primary level of education & $0.97(0.59$ to 1.59$)$ & - & $1.46(0.91$ to 2.34$)$ & - \\
\hline Family income $<1 \mathrm{MW}$ & $1.05(0.58$ to 1.89$)$ & - & 1.47 (0.81 to 2.67$)$ & - \\
\hline Family income $\geq 1<2 \mathrm{MW}$ & $0.90(0.48$ to 1.71$)$ & - & $1.17(0.61$ to 2.24$)$ & - \\
\hline \multicolumn{5}{|l|}{ Family environment } \\
\hline Exposure to tobacco & $1.16(0.72$ to 1.87$)$ & - & $1.22(0.80$ to 1.85$)$ & - \\
\hline Exposure to mould & $1.29(0.82$ to 2.03$)$ & - & $1.73(1.14$ to 2.63$)$ & - \\
\hline Number of children $\geq 2$ & $1.23(0.80$ to 1.88$)$ & - & $0.87(0.59$ to 1.27$)$ & - \\
\hline \multicolumn{5}{|l|}{ Psychosocial factors } \\
\hline Suspected CMD & $2.01(1.31$ to 3.11$)$ & 1.74 (1.12 to 2.71$)$ & 1.97 (1.35 to 2.86$)$ & 1.73 (1.17 to 2.55$)$ \\
\hline High affective support & $0.82(0.51$ to 1.31$)$ & $0.85(0.52$ to 1.37$)$ & $0.65(0.43$ to 0.96$)$ & $0.67(0.45$ to 1.01$)$ \\
\hline High material support & $0.76(0.48$ to 1.19$)$ & $0.76(0.48$ to 1.20$)$ & $0.64(0.43$ to 0.95$)$ & $0.63(0.42$ to 0.95$)$ \\
\hline High positive social interaction & $0.98(0.62$ to 1.55$)$ & 1.02 (0.64 to 1.63$)$ & $0.69(0.46$ to 1.02$)$ & $0.69(0.46$ to 1.03$)$ \\
\hline High emotional support & $0.76(0.47$ to 1.23$)$ & $0.82(0.50$ to 1.35$)$ & $0.83(0.55$ to 1.26$)$ & $0.88(0.57$ to 1.34$)$ \\
\hline High informational support & $0.98(0.61$ to 1.56$)$ & $0.96(0.60$ to 1.55$)$ & $0.61(0.41$ to 0.90$)$ & $0.60(0.40$ to 0.90$)$ \\
\hline
\end{tabular}

The bold values represent the statistically significant $p$ values.

*Adjusted for education, maternal history of asthma, exposure to mould, child's age and history of pneumonia.

$\mathrm{CMD}$, common mental disorder. 
Table 3 Confounding evaluation for the association between maternal CMD and prevalence of atopic and non-atopic wheezing by condition of exposure and outcome

\begin{tabular}{|c|c|c|c|}
\hline \multirow[b]{2}{*}{ Potentially confounding variables } & \multirow[b]{2}{*}{$\begin{array}{l}\text { No asthma symptoms } \\
(\mathrm{N}=481), \text { OR }(95 \% \mathrm{CI})\end{array}$} & \multicolumn{2}{|c|}{ No suspected CMD (N=631) } \\
\hline & & $\begin{array}{l}\text { Atopic asthma } \\
\text { symptoms, OR (95\% CI) }\end{array}$ & $\begin{array}{l}\text { Non-atopic asthma } \\
\text { symptoms, OR (95\% CI) }\end{array}$ \\
\hline Maternal history of asthma & $2.30(1.34$ to 3.96$)$ & 3.96 (1.70 to 9.22$)$ & $2.36(1.15$ to 4.82$)$ \\
\hline Child's age & $1.21(0.83$ to 1.76$)$ & $1.61(0.91$ to 2.85$)$ & 1.89 (1.08 to 3.32$)$ \\
\hline
\end{tabular}

informational supports (62.8\%) compared with the group without CMD symptoms (table 1$)$.

Children under 7 years old, or with a history of pneumonia, or whose mothers presented with suspected CMD had a greater likelihood of atopic and non-atopic asthma symptoms. In contrast, affective, material and informational supports demonstrated negative associations with non-atopic wheezing only, as well as with exposure to mould and maternal level of education. Furthermore, maternal history of asthma was associated with the occurrence of atopic and non-atopic asthma symptoms (table 2).

In the multivariate analysis, suspected maternal CMD was associated with atopic and non-atopic asthma symptoms when adjusted for education, maternal history of asthma, exposure to mould, child's age and history of pneumonia. We maintained the same multivariate model to test association between social support and asthma symptoms, and we found that high material and informational supports were negatively associated with non-atopic wheezing.

To evaluate whether maternal asthma history and child's age were confounding variables, we estimated their associations with suspected maternal CMD in the group of non-asthmatic children and simultaneously with atopic and non-atopic wheezing in the group of mothers with no CMD symptoms. Maternal history of asthma was a potential confounder since it increased the probability of $\mathrm{CMD}$ prevalence among mothers with non-asthmatic children and was also associated with atopic and non-atopic asthma symptoms in the group of mothers without CMD. Child's age was not a confounding factor of the association between $\mathrm{CMD}$ and atopic and non-atopic asthma (table 3). Comparing the saturated and reduced models for maternal history of asthma, we observed a $7.5 \%$ increase of estimated OR between $\mathrm{CMD}$ and atopic asthma symptoms, and the likelihood ratio test rejected the hypothesis that the reduced model was more appropriate ( $\mathrm{p}$ value $=0.000$ ).

To identify the existence of effect modification, we started out with the hypothesis that in the low social support group, the association between maternal CMD and both asthma outcomes would be stronger and that in the high social support group, this association would be weaker, due to the moderator effect of this condition on maternal stress and its probable consequences for asthma occurrence.

In tables 4 and 5, we present the OR for association between maternal $\mathrm{CMD}$ and atopic and non-atopic wheezing in each stratum of affective, material and informational support.
Although there is a trend for ORs to be higher when the level of social support is lower, we did not find effect modification.

\section{DISCUSSION}

We found similar associations between suspected maternal $\mathrm{CMD}$ and asthma symptoms among atopic and non-atopic children. This finding is compatible with previous studies which have identified the contribution of maternal mental health to an increase in the prevalence of atopic and non-atopic wheezing in children. ${ }^{17}$

As maternal history of asthma is an important confounding factor in other asthma studies, ${ }^{2-4} 7$ we kept this variable in the model to estimate the association between maternal CMD and asthma symptoms. A robust association between maternal $\mathrm{CMD}$ and both asthma phenotypes examined here was maintained even after adjusting for this potential confounder, which indicates that the effect of maternal mental health on childhood wheezing is independent of the child's exposure to the other biological or environmental risk factors studied in this project. This finding provides support to the hypotheses that the experience of chronic family stress affects the occurrence of asthma symptoms; it has been suggested that this is mediated by changes in certain inflammatory markers associated with the atopic and non-atopic profiles. 918

We also identified the protective effect of material and informational social supports, a result that is consistent with previous findings in this area. ${ }^{10} 20$ It has recently been reported that high levels of social support received by the family reduced the risk of the child presenting with asthma by $34 \% .{ }^{10}$ It has also been observed that low levels of family support are associated with an increase in asthma symptoms and with alterations in the pulmonary function of adolescents. ${ }^{20}$

In this study, the independent protective effect of social support was only found in non-atopic wheezing, supporting the hypothesis that the effects of psychosocial factors are more relevant to non-atopic asthma than to atopic asthma. Furthermore, our findings point to an intriguing possibility that the material and affective supports may act as a buffer for the impact of maternal mental disorder on non-atopic wheezing, although this was not statistically significant. This may be due to the reduced size of each stratum and the consequent reduction of the study power, as well as to the smaller size of the groups because of the two outcomes. However, it is also possible that social support does not function as a moderator of the impact of maternal CMD on non-

Table 4 Effect modification for the association between suspected maternal CMD and non-atopic asthma symptoms, according to affective, material and informational social support

\begin{tabular}{|c|c|c|c|c|c|c|}
\hline & \multicolumn{2}{|c|}{ Affective support } & \multicolumn{2}{|c|}{ Material support } & \multicolumn{2}{|c|}{ Informational support } \\
\hline & High, OR (95\% Cl) & Low, OR (95\% Cl) & High, OR (95\% Cl) & Low, OR (95\% Cl) & High, OR (95\% Cl) & Low, OR (95\% CI) \\
\hline Suspected CMD & 1.43 (0.87 to 2.35$)$ & 2.21 (1.10 to 4.46$)$ & $1.41(0.85$ to 2.33$)$ & $2.12(1.08$ to 4.15$)$ & $1.61(0.97$ to 2.68$)$ & 1.60 (0.84 to 3.03$)$ \\
\hline
\end{tabular}


Table 5 Effect modification for the association between suspected maternal CMD and atopic asthma symptoms, according to affective, material and informational social support

\begin{tabular}{|c|c|c|c|c|c|c|}
\hline & \multicolumn{2}{|c|}{ Affective support } & \multicolumn{2}{|c|}{ Material support } & \multicolumn{2}{|c|}{ Informational support } \\
\hline & High, OR (95\% CI) & Low, OR (95\% CI) & High, OR (95\% Cl) & Low, OR (95\% CI) & High, OR (95\% CI) & Low, OR (95\% CI) \\
\hline Suspected CMD & 1.86 (1.09 to 3.19$)$ & 1.39 (0.61 to 3.17$)$ & 1.59 (0.93 to 2.76$)$ & 1.77 (0.81 to 3.87$)$ & 1.59 (0.94 to 2.69$)$ & $2.0(0.86$ to 4.64$)$ \\
\hline
\end{tabular}

CMD, common mental disorder.

atopic asthma and is a distal determinant of maternal mental health, acting in a chain of events related to the occurrence of the disease.

The mechanism of the action of social support on occurrence of maternal CMD and childhood asthma is not clear. Intervention studies have demonstrated that an increased perception of social support is associated with a reduction of maternal symptoms of anxiety/depression, as well as providing parents with a sense of self-efficacy. ${ }^{19-21}$ It is possible, therefore, that mothers with material and affective social support present with fewer symptoms of anxiety/depression and perceive themselves as more effective child carers, which influences their ability to adapt to the child's demands and to provide more adequate preventive and curative care.

One important study limitation is its cross-sectional design, which does not allow us to assert temporality in the relationships established here. Although recent evidence from the literature corroborates the association in the direction presented here 111214151718 , new longitudinal studies are required in order to corroborate the hypotheses and findings presented. Furthermore, despite utilising validated questionnaires and broad support from the literature, the exposure and outcome measures may be subject to respondent bias since anxious/depressive parents (who also tend to be from families with lower incomes and probably have less access to healthcare) tend to report more asthma symptoms in their children and have a more pessimistic view of reality. ${ }^{16} 17$

Finally, these findings could have important implications for the implementation of public policies for the prevention and management of childhood asthma, by highlighting the importance of both maternal mental healthcare and the strengthening of social ties in order to promote the physical and psychological well-being of the child. Whether or not these factors are taken

\section{What is already known on this subject}

Psychosocial factors are associated with childhood asthma expression and morbidity, albeit studies to date have not considered possible differential effects on atopic versus nonatopic phenotypes.

\section{What this study adds}

The harmful effect of poor maternal mental health does not differ between atopic and non-atopic wheezing, while perception of family social support appears to buffer this relationship in nonatopic wheezers only. into consideration will either enhance or hinder efficiency in the care of asthma symptoms.

Acknowledgements We would like to thank all the parents and children who participated in this study and Leila Denise Alves Ferreira Amorim for statistical support.

Contributors LMdS was involved in data analysis and interpretation as well as in writing the first draft of the study. DNdS was involved in the study planning and design, data analysis and interpretation and helped to review the study draft. LCR was involved in the study planning and design, data analysis and interpretation and helped to review the study draft. MLB, principal investigator of the main study from which this present study was derived, was involved in the study planning and design, data interpretation and helped to review the study draft.

Funding Wellcome Trust, UK, HCPC Latin American Centres of Excellence Programme (ref 072405/Z/03/Z). The funders had no role in study design, data collection and analysis, the decision to publish or the preparation of the manuscript.

\section{Competing interests None.}

Ethics approval The study was approved by the National Ethics Committee in 2005, registration number 047-05/CEP-ISC FR-78168.

Provenance and peer review Not commissioned; externally peer reviewed.

\section{REFERENCES}

1. Cunha SS, Barreto ML, Fiaccone RL, et al. Asthma cases in childhood attributed to atopy in tropical area in Brazil. Pan Am J Public Health 2010;28:405-11.

2. Pearce N, Pekkanen J, Beasley R. How much asthma is really attributable to atopy? Thorax 1999;54:268-72.

3. Cooper PJ, Rodrigues LC, Cruz AA, et al. Asthma in Latin America: a public health challenge and research opportunity. Allergy 2009;64:5-17.

4. Moncayo AL, Vaca M, Oviedo G, et al. Risk factors for atopic and non-atopic asthma in a rural area of ecuador. Thorax 2010:65:409-16.

5. Fan Y. Clinical types of childhood asthma and nonatopic asthma. World J Pediatr 2006;2:85-9.

6. Martinez FD. Development of wheezing disorders and asthma in preschool children. Pediatrics 2002;109:362-7.

7. Donovan CE, Finn PW. Immune mechanisms of childhood asthma. Thorax 1999:54:938-46.

8. Rönmark $\mathbf{E}$, Jönsson E, Platts-Mills T, et al. Different pattern of risk factors for atopic and nonatopic asthma among children-report from the obstructive lung disease in Northern Sweden Study. Allergy 1999:54:926-35.

9. Wright RJ, Finn P, Contreras JP, et al. Chronic caregiver stress and IgE expression, allergen-induced proliferation, and cytokine profiles in a birth cohort predisposed to atopy. J Allergy Clin Immunol 2004;113:1051-7.

10. Shalowitz MU, Mijanovich T, Berry CA, et al. Context matters: a community-based study of maternal mental health, life stressors, social support, and children's asthma. Pediatrics 2006;117:e940-8.

11. Berz JB, Carter AS, Wagmiller RL, et al. Prevalence and correlates of early onset asthma and wheezing in a healthy birth cohort of 2- to 3-year olds. J Ped Psychol 2007;32:154-66.

12. Ortega AN, Goodwin RD, McQuaid EL, et al. Parental mental health, childhood psychiatric disorders, and asthma attacks in Island Puerto Rican youth. Amb Ped 2004;4:308-15.

13. Barreto do Carmo MB, Santos DN, Amorim LDAF, et al. Minor psychiatric disorders in mothers and asthma in children. Soc Psychiatry Psychiatr Epidemiol 2008;10:1483-8

14. Wright R, Cohen S, Carey V, et al. Parental stress as a predictor of wheezing in infancy: a prospective birth-cohort study. Am J Respir Crit Care Med 2002; 165:358-65.

15. Kozyrskyj AL, Mai XM, McGrath $\mathrm{P}$, et al. Continued exposure to maternal distress in early life is associated with an increased risk of childhood asthma. Am J Resp Crit Care Med 2008;177:142-7.

16. Martinez KG, Pérez EA, Ramírez $\mathrm{R}$, et al. The role of caregivers' depressive symptoms and asthma beliefs on asthma outcomes among low-income Puerto Rican children. J Asthma 2009:46:136-41.

17. Cookson H, Granell R, Joinson C, et al. Mothers' anxiety during pregnancy is associated with asthma in their children. J Allergy Clin Immunol 2009;123:847-85. 
18. Wolf JM, Miller GE, Chen E. Parent psychological states predict changes in inflammatory markers in children with asthma and healthy children. Brain Behav Immun 2008;22:433-41.

19. Mangan JM, Wittich AR, Gerald LB. The potential for reducing asthma disparities through improved family and social function and modified health behaviors. Chest 2007:132:789-801.

20. Chen $\mathbf{E}$, Chim LS, Strunk RC, et al. The role of the social environment in children and adolescents with asthma. Am J Respir Crit Care Med 2007;176:644-9.

21. Kaugars AS, Klinnert MD, Bender BG. Family influence on pediatric asthma. J Ped Psychol 2003;29:475-91.

22. Barreto ML, Cunha SS, Alcântara-Neves N, et al. Risk factors and immunological pathways for asthma and other allergic diseases in children: background and methodology of a longitudinal study in a large urban center in Northeastern Brazil (Salvador-SCAALA study). BMC Pulm Med 2006:23:6-15.
23. Asher MI, Keil U, Anderson HR, et al. International study of asthma and allergies in childhood (ISAAC): rationale and methods. Eur Respir J 1995;8:483-91.

24. Mari JJ, Williams P. A validity study of a psychiatric screening questionnaire (SRO 20) in primary care in the city of São Paulo. Br J Psychiatry 1986: 148:23-6.

25. Griep RH, Chor D, Faerstein E, et al. Validade de constructo de escala de apoio social do medical outcomes study adaptada para o português no Estudo Pró-Saúde. Cad Saúde Pública 2005;21:703-14.

26. Gonçalves DM, Stein AT, Kapczinski F. Performance of the self-reporting questionnaire as a psychiatric screening questionnaire: a comparative study with structured clinical interview for DSM-IV-TR. Cad Saúde Pública 2008;24:380-90.

27. Hosmer DW, Lemeshow S. Applied Logistic Regression. 2 edn. New York: John Wiley \& Sons Inc, 2000. 